\title{
DUSTING OFF THE PERCEPTION OF RISK AND RETURNS IN FOREX MARKETS
}

\author{
PHORNCHANOK CUMPERAYOT
}

\author{
CESIFO WORKING PAPER NO. 904
}

CATEGORY 6: MONETARY POLICY AND INTERNATIONAL FINANCE

APRIL 2003

Presented at CESifo Venice Summer Institute 2002

\footnotetext{
An electronic version of the paper may be downloaded

- from the SSRN website: Www.SSRN.com

- from the CESifo website: www.CESifo.de
} 


\title{
DUSTING OFF THE PERCEPTION OF RISK AND RETURNS IN FOREX MARKETS
}

\begin{abstract}
In this paper, we construct alternative theoretical models for exchange rates by introducing additional risk factors, based on the volatility of macroeconomic fundamentals. The modified flexible-price monetary model is used to characterize the long-run equilibrium of exchange rates, while the modified sticky-price model explains the adjustment towards the long run. Empirically, in a number of OECD countries we find cointegration relationships between the exchange rate and macroeconomic variables and also some evidence for the long-run equilibrium error correction. Macroeconomic uncertainty can significantly explain the variation of the exchange rate from its fundamental-based value. The results lead us to believe that macroeconomic sources of FOREX risk may be a missing factor in the exchange rate study.
\end{abstract}

JEL Code: E44, F31, G12.

Keywords: flexible-price and sluggish-price exchange rate models, expectation formations, macroeconomic risk, risk premium, asset pricing.

\author{
Phornchanok Cumperayot \\ Faculty of Economics \\ Chulalongkorn University \\ Bangkok 10330 \\ Thailand \\ cumperayot@few.eur.nl
}

The author would like to thank Paul de Grauwe, Roy Kouwenberg, Antonio Garcia Pascual, Mark Taylor and Casper de Vries for useful discussions and thoughtful comments, and also Namwon Hyung for econometric tips. 


\section{Introduction}

After the demise of the Bretton Woods system in early 1973, many industrialized countries turned to a (semi) floating exchange rate regime. ${ }^{1}$ Academics try to explain causes of exchange rate fluctuations and search for policy recommendations. There are numerous papers trying to explain the movement of exchange rates. ${ }^{2}$ Many theoretical attempts, however, fail to determine exchange rates in practice. Empirical investigations have been carried out to test the exchange rate theories

\footnotetext{
${ }^{1}$ This articile is partially from Chapter 2 „Modeling Currency Prices“ in a doctoral thesis by Cumperayot (2002).

${ }^{2}$ For example. For the monetary-approach partial equilibrium models Frenkel (1976), Mussa (1976) and Bilson (1978) discuss the flexible-price model, while Dornbusch (1976), Frankel (1979), Mussa (1979) and Buiter and Miller (1982) consider the sticky-price model. The general equilibrium asset pricing models are studied by Stockman (1980), Lucas (1982), Svensson (1985a, b) and Hodrick (1989), and extended into the continuous-time stochastic framework by Bakshi and Chen (1997) and Basak and Gallmeyer (1998).
} 
and the predictability of exchange rates. ${ }^{3}$ The empirical support for the theories has been rather weak.

In this paper, a nonlinear model for exchange rates is proposed, based on the monetary exchange rate theory and the theory of financial asset pricing, so as to provide alternative insights about the anomalous behavior of exchange rates. This paper is inspired by the pioneering work of Hodrick (1989), in which the volatility of macroeconomic fundamentals are introduced in the exchange rate model as additional risk factors. Dissimilar to Hodrick (1989), we incorporate macroeconomic risk into the flexible-price and the sluggish-price monetary models, which allow us to examine long-run and short-run effects of the fundamental uncertainty. Moreover, our empirical results are rather striking and supportive compared to Hodrick (1989).

In the long run, we find that an increase in the domestic money supply or a decrease in domestic real income leads depreciation of the domestic currency, and vice versa for the foreign variables. Time-varying conditional variances of the macroeconomic variables, representing macroeconomic risk, can significantly explain the deviation of the exchange rate from its fundamental-based value. Macroeconomic uncertainty influences the perception of FOREX risk and consequently influences market expectations about compensation for risk bearing. Due to risk aversion, high risk is accompanied by high expected future returns, or equivalently a current depreciation of the currency. In the short run, we find evidence for correction of equilibrium errors towards the long-run equilibrium.

We conclude that macroeconomic sources of FOREX risk may be a missing factor in exchange rate studies and that the monetary-approach models could potentially still be usefulness. The next section gives the motivation of our work. In Section 3 , we discuss the nonlinear dynamic model. Its econometric results are reported in Section 4, while Section 5 contains conclusions.

\section{Motivation for the Model}

The monetary approach to model exchange rates has been viewed as one of the most dismal failures in modern economics, see Flood and Rose (1999). Nevertheless, we can hardly deny that for our anticipation of exchange rates we rely on economic fundamentals, and often in the manner predicted by the monetary-based exchange rate models. Inspired by the works of Dornbusch (1976) and Hodrick (1989), we establish a model for exchange rates by reconsidering the expectation assumptions used in the traditional exchange rate models and by exploiting the statistical regularity of time-varying conditional variances of fundamental growth rates. As suggested in Dornbusch (1976), a fundamental change from its equilibrium level may cause a short-run overshooting in the exchange rate.

Volatility in the macroeconomic variables may consequently induce volatility in the exchange rate. As a result, uncertainty in macroeconomic fundamentals may influence the perception of risk in the markets, and subsequently through the risk premium it may price returns on the exchange rate, as stated in Hodrick (1989). This seems a natural idea for explaining the exchange rate risk premium, arising from variation in conditional variances of exchange rate returns, but Hodrick (1989) finds little support for the idea. After more than a decade since his research and almost three decades of floating exchange rate regime, it is timely to reinvestigate the hypothesis in Hodrick (1989).

\footnotetext{
${ }^{3}$ To name but a few, the empirical studies have been done by Frenkel (1976), Bilson (1978), Hodrick (1978, 1989), Meese and Rogoff (1983, 1988), Backus (1984), Meese (1990), MacDonald and Taylor (1994), Chinn and Meese (1995), Mark (1995) and Flood and Rose (1995, 1999).
} 
In the literature, exchange rates rely on two factors, which are the current fundamental levels, $\widetilde{f}_{t}$, and the expectation of future exchange rates, $E_{t}\left[e_{t+1}\right] .^{4} \mathrm{~A}$ general framework of the models in the exchange rate literature can be summarized as shown in Cuthbertson $(1999)^{5}$,

$$
e_{t}=E_{t}\left[e_{t+1}\right]-\alpha \tilde{f}_{t},
$$

where $e_{t}$ is the logarithm of the nominal exchange rate, $\widetilde{f}_{t}$ represents the fundamentals that may differ in each model, and $E_{t}[\cdot]$ is the conditional expectation operator. Apart from many possible estimation problems ${ }^{6}$, as expectations about the future exchange rate are likely to be a self-fulfilling prophecy, the expectation formation deserves considerable attention.

In the context of the present value relation, it is known that persistent movement in an asset's expected return tends to have dramatic effects on the asset price, as it makes the price more volatile than in the case of a constant expected return. ${ }^{7}$ This also holds for the currency price, for which the expected return is represented by the expected price change. However, the source of the expectation variation is an unresolved issue. In this paper, we provide an alternative explanation for the expectation formation in the exchange rate models. According to the exchange rate literature, the fundamental solution of the exchange rate is determined by the expected present value of macroeconomic fundamentals, discounted at a constant rate (following from Cuthbertson (1999) in this case is equal to one) ${ }^{8}$;

$$
e_{t}=-\sum_{i=0}^{\infty} \alpha E_{t}\left[\widetilde{f}_{t+i}\right]
$$

By comparing equation (2), i.e., $e_{t}=-\alpha \widetilde{f}_{t}-\sum_{i=1}^{\infty} \alpha E_{t}\left[\widetilde{f}_{t+i}\right]$, to equation (1), one finds that the expected future fundamentals are used to determine the expected future exchange rate. Nonetheless, in practice the structure of expectation formation is not known and the infinite horizon is not easily specified. It is often assumed that the fundamental processes are a random walk process, $E_{t}\left[x_{t+1}\right]-x_{t}=0$. As a consequence, the models are then left with the current values of the fundamentals as representatives of the expected future fundamentals, see, e.g., Meese and Rogoff (1983). As there is no expected change in the fundamentals, these rational expectation models imply zero expected exchange rate returns. Yet, empirically positive correlations of exchange rate returns are found at short horizons, whereas negative serial correlations are reported at longer horizons, see, e.g., Cuthbertson (1999).

Moreover, there is some evidence for predictability of the exchange rate at long horizons once the fundamentals are brought into the analysis. ${ }^{9}$ It is unlikely that

\footnotetext{
${ }^{4}$ Mathematical applications are partially adopted from Cuthbertson (1999).

${ }^{5}$ This equation is derived from the uncovered interest parity (UIP) and from an assumption corresponding to the monetary models that the interest rate differential depends on the fundamentals $\widetilde{f}_{t}:$$$
i_{t}-i_{t}^{*}=\alpha \widetilde{f}_{t} .
$$

${ }^{6}$ See a summary in Meese (1990).

${ }^{7}$ See Campbell, Lo and MacKinlay (1997) Chapter 7.

${ }^{8}$ This solution is derived by applying the law of iterated expectations, i.e., $E_{t}\left[E_{t+1}[X]\right]=E_{t}[X]$, to equation (1). Suppose the discount rate is lower than one, e.g., as it is governed by an interest semi-elasticity to money demand which is said to be smaller than one. The expectation would be assigned lower exponential weight (to the power $i$ ) as looking forward (to time $t+i$ ). From the Limit Theorem, at infinity $T \rightarrow \infty$ the bubble term (with a weight to the power $T+1$ ) vanishes. See also Blanchard and Fischer (1993) Chapter 5.

${ }^{9}$ For instance, MacDonald and Taylor (1994) find cointegration between exchange rates and monetary variables in the fundamental exchange rate models. Chinn and Meese (1995), as well as Mark (1995), find evidence that for long horizons the monetary-based exchange rate model
} 
the expected returns are zero. In particular, since the patterns of time variation in the mean and the variance of the fundamental changes have actually been observed. Like exchange rate returns, there is rather strong evidence of time-varying conditional variances of the fundamentals, though it is not well documented. ${ }^{10}$ As there exists systematic fundamental volatility, this paper investigates whether the fundamental uncertainty, e.g., through risk premium, can determine expected exchange rate returns and thus, the exchange rate movement.

This doctrine is similar to the well-known theme of asset pricing models, e.g., the Capital Asset Pricing Model (CAPM) developed by Markowitz (1959), Sharpe (1964) and Lintner (1965) and Arbitrage Pricing Theory by Ross (1976). The theory's goal is mainly to quantify assets' equilibrium expected returns from the risk of bearing the assets. To relate exchange rate risk and return, Fama (1984) finds that variation in risk premium in the forward exchange market is more pronounced than the expected depreciation rate, i.e., expected exchange rate return. Frankel and Meese (1987) indicate that changes in conditional variance of the exchange rate have substantial impacts on the level of the exchange rate. Hodrick's (1989) model theoretically predicts that changes in the macroeconomic variances affect risk premia and therefore, exchange rates. Yet, the empirical results are not supportive. Our model is described in the next section.

\section{The Model}

The present value of the exchange rate for the flexible-price model can be written as

$$
e_{t}=\varsigma_{0} \sum_{i=0}^{\infty} \varsigma_{2}^{i}+\varsigma_{1} \sum_{i=0}^{\infty} \varsigma_{2}^{i} E_{t}\left[\widetilde{f}_{t+i}\right]
$$

where $\widetilde{f}_{t}=\widetilde{m}_{t}-(1+\gamma) \widetilde{y}_{t}$, and $\widetilde{m}_{t}$ and $\widetilde{y}_{t}$ are the logarithms of the domestic money supply and real income with respect to the foreign levels. For the sluggish-price model, inertia is introduced into the price mechanism and thus, the exchange rate equation. Cuthbertson (1999) shows that with the UIP condition the Dornbusch model gives rise to a form similar to equation (2):

$$
e_{t}=\vartheta_{1} e_{t-1}+\lambda \sum_{i=0}^{\infty} \vartheta_{2} E_{t-1}\left[\widetilde{k}_{t+i}\right] ;\left(\vartheta_{1}, \vartheta_{2}\right)<1,
$$

where $\widetilde{k}_{t} \equiv \frac{1}{\varphi} \widetilde{f}_{t}+\frac{1-\theta}{\theta \varphi} \widetilde{f}_{t-1}$. The exchange rate now depends on $\widetilde{k}_{t}$, namely current and lagged values of money supply and real income, and its expected future values. ${ }^{11}$

Since the exchange rate is a discounted sum of expected future fundamentals, i.e., equations (2), (3) and (4), if one could specify the expectation of $\widetilde{f}$ (or $\widetilde{k}$ in a case of the sticky-price model), an explicit process of the exchange rate can then be found. A number of methods to incorporate the fundamentals' variances into their expectations are discussed in Appendix C. Here, we assume that the fundamental series can be explained by its historical values and its time-varying second

\footnotetext{
overcomes the random walk model in predicting exchange rates. Groen (1999) shows that at a pooled time series level, there is cointegration between exchange rates and macroeconomic variables in the monetary model.

${ }^{10}$ The exceptions include the studies by Cragg (1982), Engle (1982, 1983), Obstfeld (1987), Hodrick (1989), Arnold (1996) and Bekaert (1996).

${ }^{11}$ In Appendix B, we provide the derivation (in details) of the reduced-form solutions of the flexible-price and sluggish-price models. It should also be noted that for the sluggish-price model we actually work with a more complex assumption of price inertia. As a result, our solution looks tedious (but similar), compared to equation (4). Importantly, it facilitates our closed-form derivation shown next.
} 
moment. ${ }^{12}$ Therefore, the expected future fundamentals do not only depend on the current fundamental levels but also the expected variances of the fundamentals, representing how volatile the fundamentals are. An explicit solution of the flexible-price model can, then, be written as

$$
e_{t}=a_{0}+a_{1} \widetilde{m}_{t}+a_{2} \widetilde{y}_{t}+a_{3} h_{\widetilde{m}, t}+a_{4} h_{\tilde{y}, t} .
$$

In addition to the current fundamental values, the exchange rate is determined by time-varying conditional variances of the fundamentals, i.e., $h_{t}$.

For the sticky-price model, the closed-form solution is

$$
\begin{aligned}
e_{t}= & b_{0}+b_{1} e_{t-1}+b_{2} \widetilde{m}_{t}+b_{3} \widetilde{y}_{t}+b_{4} \widetilde{m}_{t-1}+b_{5} \widetilde{y}_{t-1} \\
& +b_{6} h_{\widetilde{m}, t}+b_{7} h_{\widetilde{y}, t}+b_{8} h_{\widetilde{m}, t-1}+b_{9} h_{\widetilde{y}, t-1}
\end{aligned}
$$

in which the present and lagged values of the fundamentals and their time-varying conditional variances are included in the exchange rate determination. The levels of macroeconomic fundamentals are well known to be insufficient for explaining exchange rate movements. In addition to the traditional monetary models, we introduce macroeconomic risk to describe the deviation of the excessive volatile exchange rate relative to the conventional prediction based on economic fundamentals.

In this paper, the expectations of future fundamentals are reformulated by exploiting the systematic pattern of fundamental volatility, instead of assuming a random walk process. Equations (5) and (6) similarly predict that ceteris paribus, an increase in money supply and a decrease in industrial production, relative to the foreign levels, tend to depreciate the domestic currency. Besides, we explain anomalous movements of the exchange rate, relative to the traditional paradigm, by the presence of volatility clusters in the fundamentals. ${ }^{13}$ To capture the currency price volatility, time variation in conditional variances of the fundamentals, captured by a GARCH $(1,1)$ model $^{14}$, are incorporated to describe expected exchange rate returns.

The modified flexible-price model in equation (5) is used to characterize the longrun equilibrium of exchange rates, while the modified sticky-price model in equation (6) corrects for fundamental disequilibrium. The idea to examine the long-run impacts of macroeconomic risk on the exchange rate may seem controversial at first, as one would think that the exchange rate volatility is considered as a short-term phenomenon and has nothing to do with the long run. In fact, the asset pricing models, e.g., CAPM, are used for the long-run equilibrium price determination. Intuitively, the models say that one who holds risky assets expects to be compensated at least in the long run. Similarly, our paper discusses the expected compensation from holding risky assets in both short run and long run. The next section provides the empirical investigation.

\section{Specification and Estimation}

With regard to the exchange rate level, although many developments can cause permanent changes in the exchange rate, the cointegration relationship between the spot rates and macroeconomic fundamentals implies that there is some long-run

\footnotetext{
12 The argument and derivation are in Appendix D.

${ }^{13}$ The nonlinearity in the model seems to coincide with the idea of nonlinear bubbles. For example, in Froot and Obstfeld (1991) the bubble is a nonlinear function of stock's dividend.

${ }^{14}$ A GARCH(1,1) model (with a student-t distribution, if necessary) is used to capture fundamental uncertainty. The model is considered as a parsimonious model of conditional variance that adequately fits many economic time series, see, e.g., Bollerslev (1987). It suggests a form of heteroskedasticity, in which the variance of next period shocks depends on the size of shocks in this period. Therefore, a turbulent (tranquil) period is likely to be followed by turbulent (tranquil) periods. Alternatively, news has persistent effects in some periods.
} 
equilibrium relation tying the exchange rate to its macroeconomic fundamentals, see Hamilton (1994). ${ }^{15}$ Moreover, persistent movements in the fundamental volatility are likely to have larger impacts on exchange rate risk and returns than temporary movements. To model the exchange rate, we are therefore concerned with the cointegration among the variables in equation (5), whereas equation (6) is applied as an error-correction model to explain the adjustment towards the long-run equilibrium.

Like other macroeconomic studies, this empirical study involves nonstationary and trending variables, e.g., exchange rates, money supply and industrial production. Furthermore, some GARCH series, as a proxy of time variation in conditional variances $h_{t}$, may appear to be $I(1)$ as the variance process is close to an integrated GARCH model, i.e., IGARCH. There are several ways to manipulate such series, namely to use transformations to reduce them to stationary, e.g., to use a vector autoregressive (VAR) model, or to analyze the relationship between these trending variables. Hodrick (1989) takes first differences to make the series stationary. However, in the existence of a cointegration relationship differencing the data might not be appropriate since counterproductively, it would obscure the long-run relationships between the variables.

As mentioned, we favor the latter option so as to distinguish between a long-run relationship, in which the variables drift together at roughly the same rate, and the short-run dynamics that capture the relationship between deviations of the variables from the long-run trend, see Stock and Watson (1988) and Greene (2000). It should also be noted that our analysis involves generated regressors, i.e., estimated conditional variances. According to Pagan (1984), the two-step procedure, i.e., to estimate the conditional variances from the ARCH models and to exogenously use the estimated variances in the OLS regression, can produce consistency in estimated coefficients if the ARCH processes provide consistent estimates of true conditional variances, see also Hodrick (1989). Dissimilar to Hodrick (1989), we use a GARCH $(1,1)$ model with a student-t error distribution to estimate conditional variances $h_{t} .16$

For the empirical study, we use macroeconomic series from 6 OECD countries, i.e., Canada, France, Italy, Japan, the UK and the US, that coincide with our theoretical constructs, namely exchange rates, money supply and industrial production. ${ }^{17}$ To see the role of economic fundamental uncertainty in determining the exchange rate risk and expected returns, we consider the price of a US dollar in terms of the domestic currency, as the US dollar has been recognized as a vehicle currency ${ }^{18}$. The US variables are, thus, considered as the foreign variables in the exchange rate models. According to Hodrick (1989), he finds no evidence for fundamental volatility to price exchange rates because of the weak evidence of $\mathrm{ARCH}$ at monthly exchange rates. By expanding the period employed in Hodrick (1989), we find stronger evidence of ARCH in monthly observations. ${ }^{19}$ Herein, we reexamine

\footnotetext{
${ }^{15}$ For empirical results, see, e.g., MacDonald and Taylor (1994) and Groen (1999).

${ }^{16}$ Hodrick (1989) applies the ARCH-LR test and models fundamental volatility by using an ARCH(1) model with a normal distribution.

${ }^{17}$ For more details, the reader is referred to Appendix A. We also study Austria, Germany and the Netherlands. However, there is no evidence of cointegration relationship in the case of the Netherlands, while there are ambiguous cointegration test results between the Johansen (1988) test and the augmented Engle and Granger (1987) test in the case of Austria and Germany.

${ }^{18}$ This definition is given in Krugman and Obstfeld (1997). The US dollar is broadly accepted and held as a financial asset.

${ }^{19}$ There are many studies investigating $\mathrm{ARCH}$ properties in the logarithmic changes in exchange rates. At short horizons, strong findings in weekly and daily intervals respectively have been reported by Engle and Bollerslev (1986) and Baillie and Bollerslev (1987), but due to temporal aggregation (see Drost and Nijman (1993)) rather weak evidence for monthly data has been reported by Baillie and Bollerslev (1989) and Hodrick (1989).

Within our sample, we find rather strong evidence of $\mathrm{ARCH}$ in monthly exchange rate returns and fundamental growth rates. The results of the ARCH(1)-LM test, the ARMA-GARCH mod-
} 
the question posed in Hodrick (1989).

To investigate the exchange rate determination based on equations (5) and (6), it should be noted that we look at the domestic and the foreign variables separately, not in relative terms. ${ }^{20}$ Thus, the regression equations become

$$
\begin{aligned}
e_{t}= & a_{0}+a_{1} m_{t}+a_{1, f} m_{t}^{*}+a_{2} y_{t}+a_{2, f} y_{t}^{*} \\
& +a_{3} \widehat{h}_{m, t}+a_{3, f} \widehat{h}_{m^{*}, t}+a_{\mathbf{4}} \widehat{h}_{y, t}+a_{\mathbf{4}, f} \widehat{h}_{y^{*}, t}
\end{aligned}
$$

and

$$
\begin{aligned}
e_{t}= & b_{0}+b_{1} e_{t-1}+b_{2} m_{t}+b_{2, f} m_{t}^{*}+b_{3} y_{t}+b_{3, f} y_{t}^{*} \\
& +b_{4} m_{t-1}+b_{4, f} m_{t-1}^{*}+b_{5} y_{t-1}+b_{5, f} y_{t-1}^{*} \\
& +b_{6} \widehat{h}_{m, t}+b_{6, f} \widehat{h}_{m^{*}, t}+b_{7} \widehat{h}_{y, t}+b_{7, f} \widehat{h}_{y^{*}, t} \\
& +b_{8} \widehat{h}_{m, t-1}+b_{8, f} \widehat{h}_{m^{*}, t-1}+b_{9} \widehat{h}_{y, t-1}+b_{9, f} \widehat{h}_{y^{*}, t-1}
\end{aligned}
$$

where $e$ is the logarithm of the nominal exchange rate, i.e., the price of a unit of foreign currency in terms of domestic currency, $x$ represents a domestic variable and $x^{*}$ represents a foreign (US) variable.

The method of investigation is as follows. An augmented Dickey-Fuller test is firstly applied to test the null hypothesis that the variables in equation (7) contain a unit root, i.e., an $I(1)$ series, and whether the series are integrated to the same order. If the variables are integrated to different orders, a cointegration model would not be appropriate. Secondly, the Johansen (1988) test is used to identify the number of cointegration vectors from groups of the variables. Then, by an augmented Engle and Granger (1987) test we check if the error term of the cointegration equation is an $I(0)$ series. Later on, we present the dynamic OLS estimation of equation (7) and the short-run dynamic equation (8).

The first step is to identify the appropriate degree of differencing for each series. Suppose the series of interest is $z_{t}$, then the augmented Dickey-Fuller test is based on the regression of the following equation, with or without the presence of a trend $t$ :

$$
\chi(L) \Delta z_{t}=\mu+\tau t+\beta z_{t-1}+v_{t}
$$

where

$$
\chi(L)=\mathbf{I}_{n}-\chi_{1} L-\chi_{2} L^{2}-\ldots-\chi_{p} L^{p},
$$

and $v_{t}$ is an error term. This augmented specification is then used to test the null hypothesis of a unit root in the series, i.e., $H_{0}: \beta=0$, against $H_{1}: \beta<0$. Table 1 shows the results from the augmented Dickey-Fuller tests of the null hypotheses (1) that the logarithmic level of series is an $I(1)$ series, and (2) that the logarithmic first difference of the series contains a unit root. The table displays $\widehat{\beta}$ and throughout this paper an asterisk, two asterisks and three asterisks indicate significance at the $10 \%, 5 \%$ and $1 \%$ level of significance, respectively.

According to Table 1, the economic series are likely to be $I(1)$ series. At the $1 \%$ level of significance, first differencing is appropriate to induce stationary in the

\footnotetext{
eling method and the estimated coefficients of GARCH models are available upon request.

${ }^{20}$ This is due to the fact that in most of the countries (except Canada and the UK) the Wald test can reject the restriction that the coefficients of the domestic and foreign (US) variables are significantly equal in the case of money supply and real income. The test statistics are available upon request.
} 
Table 1: Results of the augmented Dickey-Fuller unit root test

\begin{tabular}{|c|c|c|c|c|c|c|c|}
\hline \multicolumn{8}{|c|}{$\chi(L) \Delta z_{t}=\mu+\tau t+\beta z_{t-1}+v_{t}$} \\
\hline & & Canada & France & Italy & Japan & U K & US \\
\hline \multirow[t]{2}{*}{ Exchange Rate } & $e$ & -0.709 & -1.933 & -1.920 & -2.338 & -2.560 & \\
\hline & $\Delta e$ & $-7.729^{* * *}$ & $-6.873^{* * *}$ & $-6.834^{* * *}$ & $-7.212^{* * *}$ & $-7.458^{* * *}$ & \\
\hline \multirow[t]{4}{*}{ Money Supply } & $m$ & -1.591 & -2.200 & -0.965 & $-3.275^{*}$ & $-3.366^{*}$ & 1.313 \\
\hline & $\Delta m$ & $-10.710^{* * *}$ & $-10.997^{* * *}$ & $-12.714^{* * *}$ & $-12.560^{* * *}$ & $-9.798^{* * *}$ & $-7.873^{* * *}$ \\
\hline & $\widehat{h}_{m}$ & $-3.185^{* *}$ & -2.400 & $.8 .218^{* * *}$ & $-3.492^{* * *}$ & $-4.903^{* * *}$ & $.4 .043^{* * *}$ \\
\hline & $\Delta \widehat{h}_{m}$ & $-7.824^{* * *}$ & $-8.639^{* * *}$ & & & & \\
\hline \multirow[t]{4}{*}{ Industrial Production } & $y$ & -2.403 & -2.783 & -3.143 & -1.108 & -2.845 & -2.915 \\
\hline & $\Delta y$ & $-6.350^{* * *}$ & $-8.125 * * *$ & $-8.754 * * *$ & $-5.471^{* * *}$ & $-7.944^{* * *}$ & $-6.461^{* * *}$ \\
\hline & $\widehat{h}_{y}$ & $-3.179^{* *}$ & $-5.676^{* * *}$ & $-6.538^{* * *}$ & $-3.919^{* * *}$ & $-4.413^{* * *}$ & $-5.563^{* * *}$ \\
\hline & $\Delta \widehat{h}_{y}$ & $-11.059^{* * *}$ & & & & & \\
\hline
\end{tabular}

\begin{abstract}
This table gives the results of the augmented Dickey-Fuller unit root test. The test is based on the augmented equation displayed on top of the table. The specification, with or without a trend $t$ depending on its significance, is used to test the null hypothesis of a unit root in the series, i.e., $H_{0}: \beta=0$, against the alternative hypothesis of no unit root $H_{1}: \beta<0$. The test is applied to the natural logarithmic levels of exchange rate (e), money supply (m) and real income $(y)$, and also to the estimated GARCH series (h) of money growth and income growth. For the series that cannot reject the unit root at the $1 \%$ level, the test is also applied to first differences of these series. ${ }^{*}, * *$ and $* * *$ indicate significance at the $10 \%, 5 \%$ and $1 \%$ level, respectively.
\end{abstract}

natural logarithms of the exchange rate, money supply and industrial productivity. The estimated GARCH processes of the macroeconomic variables are shown to be $I(0)$, except the estimated series of the French money supply. The estimated GARCH processes of the Canadian money supply and real income exhibit trend stationarity at the $5 \%$ significance level. Therefore, the model represented by equation (7) involves the variables that can individually be either $I(0)$ or $I(1)$. The modified exchange rate equation is then tested for a cointegration relationship, i.e., if there exists a stationary linear combination of these variables. The $I(0)$ variables are introduced as exogenous regressors in the cointegration function.

Second step is to examine if there is any cointegration relationship among these $I(1)$ series, i.e., if there exists any linear combinations of these $I(1)$ variables that are $I(0)$. The Johansen (1988) test is used to serve this purpose. We apply Johansen's (1988) method and estimate the coefficient matrix in an unrestricted VAR form, then test whether one can reject the restrictions implied by the reduced rank of the matrix. ${ }^{21}$ To test for cointegration, only $I(1)$ variables are investigated against the null hypothesis that the cointegration rank is $r$ or lower. ${ }^{22}$ Table 2 reports the number of significant cointegration vectors. The likelihood ratio (LR) test can reject the null hypothesis of no cointegration in every country. At the $5 \%$ significance level, the LR test indicates 1 cointegration relationship for France, Italy and Japan, and 2 cointegration relationships in the case of Canada and the UK.

As the Johansen test predicts cointegration relationship(s) for every country, an alternative method by Engle and Granger (1987) is furthermore used to assess

\footnotetext{
${ }^{21}$ For more details, the reader is referred to Hamilton (1994) and Greene (2000).

22 The results are based on the statistics in reference to the critical values for the reduced rank test given by Osterwald-Lenum (1992). As the critical values reported by EViews do not account for the inclusion of exogenous variables, only $I(1)$ variables are tested.
} 
Table 2: Results of the Johansen cointegration test

\begin{tabular}{|c|c|c|c|c|c|}
\hline \multicolumn{6}{|c|}{$\begin{array}{l}e_{t}=a_{0}+a_{1} m_{t}+a_{1, f} m_{t}^{*}++a_{2} y_{t}+a_{2, f} y_{t}^{*} \\
\quad+a_{3} \widehat{h}_{m, t}+a_{3, f} \widehat{h}_{m^{*}, t}+a_{4} \widehat{h}_{y, t}+a_{4, f} \widehat{h}_{y^{*}, t}\end{array}$} \\
\hline & Canada & France & Italy & Japan & UK \\
\hline $\begin{array}{l}\text { Hypothesised } \\
\text { no. of ranks }\end{array}$ & $2^{* *}$ & $1^{* *}$ & $1^{* *}$ & $1^{* *}$ & $2^{* *}$ \\
\hline
\end{tabular}

This table gives the results of the Johansen cointegration test for the group of the $I(1)$ variables in the modified flexible-price model (as shown on top of the table). The test is conducted under the null hypothesis that the cointegrating rank is $r$ or lower. The table shows the number of cointegrating vectors, that cannot be rejected. ${ }^{*}, *$ and $* * *$ indicate significance at the $10 \%$, $5 \%$ and $1 \%$ level, respectively.

Table 3: Results of the augmented Engle and Granger cointegration test

\begin{tabular}{cccccc}
\hline \multicolumn{6}{c}{$\Delta \varepsilon_{t}=\phi_{0} \varepsilon_{t-1}+\phi_{1} \Delta \varepsilon_{t-1}+\ldots+\epsilon_{t}$} \\
\hline & Canada & France & Italy & Japan & UK \\
\cline { 2 - 6 }$\widehat{\phi}_{0}$ & $-3.415^{* *}$ & $-4.904^{* * *}$ & $-3.722^{* * *}$ & $-3.129^{* *}$ & $-4.522^{* * *}$
\end{tabular}

This table gives the results of the augmented Engle and Granger cointegration test on the equilibrium error $\varepsilon_{t}$. It is to test the significance of the null hypothesis that the error series contains a unit root, i.e., $H_{0}: \phi_{0}=0, H_{1}: \phi_{0}<0$. If the null hypothesis cannot be rejected, there is no cointegrating relationship. $*, * *$ and $* * *$ indicate significance at the $10 \%, 5 \%$ and $1 \%$ level, respectively.

whether linear combinations, based on the flexible-price model in equation (7), appear to be stationary. From equation (7), one may rewrite the model for the exchange rate that is suitable for the regression analysis as follows;

$$
\begin{aligned}
e_{t}= & \widehat{a}_{0}+\widehat{a}_{1} m_{t}+\widehat{a}_{1, f} m_{t}^{*}+\widehat{a}_{2} y_{t}+\widehat{a}_{2, f} y_{t}^{*} \\
& +\widehat{a}_{3} \widehat{h}_{m, t}+\widehat{a}_{3, f} \widehat{h}_{m^{*}, t}+\widehat{a}_{4} \widehat{h}_{y, t}+\widehat{a}_{4, f} \widehat{h}_{y^{*}, t}+\varepsilon_{t},
\end{aligned}
$$

where $\varepsilon_{t}$ is an error term. In equation (9), the cointegration function represents the long-run movement of exchange rates. OLS estimation is applied because it has been proved to yield asymptotically superconsistent estimators when estimating cointegration relationships, see Greene (2000). The Engle and Granger (1987) twostep procedure test is applied to examine the stationarity of the residual term $\varepsilon_{t}$.

To correct for autocorrelation in the equilibrium error series, an augmented Engle and Granger test is based on estimating

$$
\Delta \varepsilon_{t}=\phi_{0} \varepsilon_{t-1}+\phi_{1} \Delta \varepsilon_{t-1}+\ldots+\epsilon_{t}
$$

under the Newey-West approach. If one cannot reject the null hypothesis of a unit root in the residual series $\left(H_{0}: \phi_{0}=0, H_{1}: \phi_{0}<0\right)$, there is no cointegration relationship between the variables in the model. Table 3 shows $\widehat{\phi}_{0}$. Asterisks indicate that the null hypothesis of unit root can be rejected at the $5 \%$ significance level for Canada and Japan, and at the $1 \%$ level for France, Italy and the UK. Table 2 and 3 demonstrate the evidence of cointegration in these countries. 
To test our assumption regarding the expectation formation that incorporates macroeconomic uncertainty, we firstly deal with the modified flexible-price model, and then the modified sluggish-price model. The Stock and Watson (1993) dynamic OLS estimation method is employed to regress the logarithm of the exchange rate against the logarithms of money supply and industrial production, and the estimated conditional variances (from a $\operatorname{GARCH}(1,1)$ model) of the growth rates of money supply and industrial production. The US variables are used as the foreign variables. Although the OLS estimation has been proved to asymptotically yield superconsistent estimates, due to the possibility that the explanatory variables are contemporaneously correlated with the disturbance term, the OLS regression coefficients are likely to be inconsistent. ${ }^{23}$ The dynamic OLS procedure, on the other hand, is robust to small sample size and simultaneity bias.

To eliminate the effects of these correlations, we apply the Stock and Watson (1993) dynamic OLS approach by adding the one period leads and lags of the first differences of the regressors mentioned above. ${ }^{24}$ The method is also known for being a robust single equation that corrects for stochastic-regressor endogeneity. According to equation (7), the dynamic OLS equation is

$$
\begin{aligned}
e_{t}= & \widehat{a}_{0}+\widehat{a}_{1} m_{t}+\widehat{a}_{1, f} m_{t}^{*}+\widehat{a}_{2} y_{t}+\widehat{a}_{2, f} y_{t}^{*} \\
& +\widehat{a}_{3} \widehat{h}_{m, t}+\widehat{a}_{3, f} \widehat{h}_{m^{*}, t}+\widehat{a}_{4} \widehat{h}_{y, t}+\widehat{a}_{4, f} \widehat{h}_{y^{*}, t}+\widehat{a}_{5} \Delta m_{t+1}+\widehat{a}_{5, f} \Delta m_{t+1}^{*} \\
& +\widehat{a}_{6} \Delta y_{t+1}+\widehat{a}_{6, f} \Delta y_{t+1}^{*}+\widehat{a}_{7} \Delta \widehat{h}_{m, t+1}+\widehat{a}_{7, f} \Delta \widehat{h}_{m^{*}, t+1}+\widehat{a}_{8} \Delta \widehat{h}_{y, t+1}(10) \\
& +\widehat{a}_{8, f} \Delta \widehat{h}_{y^{*}, t+1}+\widehat{a}_{9} \Delta m_{t-1}+\widehat{a}_{9, f} \Delta m_{t-1}^{*}+\widehat{a}_{10} \Delta y_{t-1}+\widehat{a}_{10, f} \Delta y_{t-1}^{*} \\
& +\widehat{a}_{11} \Delta \widehat{h}_{m, t-1}+\widehat{a}_{11, f} \Delta \widehat{h}_{m^{*}, t-1}+\widehat{a}_{12} \Delta \widehat{h}_{y, t-1}+\widehat{a}_{12, f} \Delta \widehat{h}_{y^{*}, t-1}+\xi_{t},
\end{aligned}
$$

where $\xi_{t}$ denotes the error term. Table 4 contains the estimated parameters from equation (10), $\widehat{a}_{i}$ and $\widehat{a}_{i, f}$ when $i=1, \ldots, 4$. An asterisk, two asterisks and three asterisks indicate significance at the $10 \%, 5 \%$ and $1 \%$ level of significance, respectively.

Apart from allowing us to examine the long-run impacts of macroeconomic risk on exchange rates, adding the estimated macroeconomic risk into a cointegration equation may help reduce the problem of omitted variables. ${ }^{25}$ From Table 4, the estimated coefficients of money supply and real income have signs as expected in the literature. In the long run, an increase in the domestic money supply or a decrease in the foreign money supply tends to depreciate the domestic currency, except for Canada. Higher domestic output or lower foreign output is likely to appreciate the domestic currency (though there are exceptions for Canada and Japan).

For Canada and the UK, at the $5 \%$ significance level the Wald test cannot reject the null hypothesis that the coefficients of domestic and foreign macroeconomic variables, like money supply and real income, are significantly equal. When we restrict the domestic and foreign coefficients of money supply and real income to be equal in these countries, in relative to the US levels higher money supply or lower

\footnotetext{
${ }^{23}$ However, if the explanatory variables and the disturbance term are not independent but they are contemporaneously uncorrelated, the OLS retains its desirable properties, see Dougherty (1992).

${ }^{24}$ According to Hamilton (1994), the similar method has been suggested by Saikkonen (1991) and Phillips and Loretan (1991).

${ }^{25}$ It should also be stressed that this approach is not exposed to the simultaneity bias. To avoid the simultaneity bias (or other violation of the fourth Gauss-Markov condition, e.g., from stochastic regressors or measurement errors), we use instrumental variables that are highly correlated with the regressors but not correlated to the error terms. In this paper, rather than using the true conditional variances, whose random components may be correlated with error terms in the exchange rate equation, we use the predicted values of the endogenous explanatory variables, i.e., the GARCH forecast of volatility. By using the forecasts which are functions of the squared lagged residual and the estimated variances from the previous period, we eliminate the random components in the fundamentals' conditional variances.
} 
Table 4: Parameters of the modified flexible-price model

\begin{tabular}{cccccc}
\hline \hline \multicolumn{6}{c}{$e_{t}=\widehat{a}_{0}+\widehat{a}_{1} m_{t}+\widehat{a}_{1, f} m_{t}^{*}++\widehat{a}_{2} y_{t}+\widehat{a}_{2, f} y_{t}^{*}$} \\
$+\widehat{a}_{3} \widehat{h}_{m, t}+\widehat{a}_{3, f} \widehat{h}_{m^{*}, t}+\widehat{a}_{4} \widehat{h}_{y, t}+\widehat{a}_{4, f} \widehat{h}_{y^{*}, t}+\ldots$ \\
\hline$\widehat{a}_{0}$ & Canada & France & Italy & Japan & UK \\
\cline { 2 - 6 }$\widehat{a}_{1}$ & $-3.128^{* * *}$ & $6.740^{* * *}$ & $6.210^{* * *}$ & $7.472^{* * *}$ & $3.868^{* * *}$ \\
$\widehat{a}_{1, f}$ & -0.116 & $0.753^{* * *}$ & $0.929^{* * *}$ & $0.774^{* * *}$ & $0.321^{* *}$ \\
$\widehat{a}_{2}$ & $0.535^{* *}$ & $-0.580^{* * *}$ & $-0.666^{* * *}$ & $-1.101^{* * *}$ & 0.097 \\
$\widehat{a}_{2, f}$ & 0.076 & $0.479^{* *}$ & $-2.056^{* * *}$ & $0.538^{* *}$ & $-1.266^{* *}$ \\
$\widehat{a}_{3}$ & $116.328^{* * *}$ & $-530.64^{* * *}$ & $-497.51^{*}$ & $-1.444^{* * *}$ & 0.029 \\
$\widehat{a}_{3, f}$ & $1356.045^{* *}$ & $-3185.05^{* *}$ & $-4555.66^{* *}$ & -1840.97 & $-6340.388^{* * *}$ \\
$\widehat{a}_{4}$ & $178.947^{* * *}$ & $376.15^{* *}$ & $46.59^{* *}$ & $270.166^{*}$ & $-172.19^{*}$ \\
$\widehat{a}_{4, f}$ & -25.750 & 6.369 & -433.14 & $-555.754^{* *}$ & $-777.12^{* * *}$
\end{tabular}

This table gives the estimation results of the modified flexible-price model, based the $\mathrm{S}$ tock and Watson (1993) dynamic OLS approach. It contains the estimated parameters, $\widehat{a}_{i}$ and $\widehat{a}_{i, f}$ when $i=1, \ldots, 4$. An asterisk, two asterisks and three asterisks indicate significance at the $10 \%, 5 \%$ and $1 \%$ level of significance, respectively.

real income tends to depreciate the domestic currencies, while the coefficients of macroeconomic risk are similar to Table $4 .^{26}$

Significantly, an increase in the money supply volatility, regardless of domestic and foreign sources, depreciates the Canadian dollar, while appreciates other currencies. For uncertainty in real income, the results significantly show that an increase in the domestic volatility depreciate the domestic currency (except the UK), whereas an increase in the foreign volatility appreciate the domestic currency. Higher uncertainty in the US real income or the US money supply raises the expected future returns on the US dollars by pushing down the current US dollar price. It consequently causes the domestic currency to appreciate (except Canada). By the same argument, uncertainty in the domestic real income is positively related to the US dollar exchange rates. It leads to an upward bias in the variation of actual exchange rates from the prediction of the traditional model.

From the table, macroeconomic uncertainty, represented by the conditional variances of money supply and real income, can explain the deviation of the exchange rate from its fundamental-based value. Uncertainty about the economy seems to lower the demand for the currency and subsequently depreciate its currency, relative to the fundamental benchmark value. From an asset pricing perspective, higher risk should be accompanied by higher expected future returns, leading to a current depreciation of the currency.

However, the opposite impact can also be observed in some cases. For every

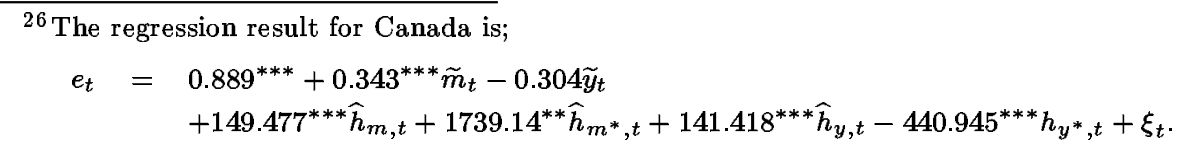

The regression result for the UK is;

$$
\begin{aligned}
e_{t}= & 0.320+0.119 \widetilde{m}_{t}-0.566^{*} \widetilde{y}_{t} \\
& -1500.33^{* * *} \widehat{h}_{m, t}-5263.13^{* * *} \widehat{h}_{m^{*}, t}-315.254^{* * *} \widehat{h}_{y, t}-341.454 h_{y^{*}, t}+\xi_{t} .
\end{aligned}
$$


country except Canada, higher volatility in the domestic money supply tends to increase the domestic currency prices. This might be because a volatile domestic monetary policy, e.g. central bank intervention to stabilize the economy, can provide a positive outlook on the domestic currency. Due to these positive aspects of macroeconomic risk (intervention), economic agents prefer to hold their local currencies and are willing to pay a higher price. The case of the UK also reveals a strong preference for the domestic currency, which is parallel to the Equity Home Bias that has been long studied in finance. ${ }^{27}$ On the other hand, for Canada the country that moves along with the US there exists a negative risk premium towards the US dollar which shows a trust in the volatile US monetary policy.

The modified sticky-price model extends the cointegration relationship between the exchange rate and its fundamentals by adding the long-run equilibrium error adjustment. By rearranging equation (8), one obtains a form of the error-correction model

$$
\begin{aligned}
\Delta e_{t}= & \widehat{b}_{0}+\widehat{b}_{2} \Delta m_{t}+\widehat{b}_{2, f} \Delta m_{t}^{*}+\widehat{b}_{3} \Delta y_{t}+\widehat{b}_{3, f} \Delta y_{t}^{*} \\
& +\widehat{b}_{6} \Delta \widehat{h}_{m, t}+\widehat{b}_{6, f} \Delta \widehat{h}_{m^{*}, t}+\widehat{b}_{7} \Delta \widehat{h}_{y, t}+\widehat{b}_{7, f} \Delta \widehat{h}_{y^{*}, t} \\
& +\left(\widehat{b}_{1}-1\right)\left\{\begin{array}{c}
e_{t-1}-\widehat{c}_{1} m_{t-1}-\widehat{c}_{1, f} m_{t-1}^{*}-\widehat{c}_{2} y_{t-1}-\widehat{c}_{2, f} y_{t-1}^{*} \\
-\widehat{c}_{3} \widehat{h}_{m, t-1}-\widehat{c}_{3, f} \widehat{h}_{m^{*}, t-1}-\widehat{c}_{4} \widehat{h}_{y, t-1}+\widehat{c}_{4, f} \widehat{h}_{y^{*}, t-1}
\end{array}\right\}+\nu_{t},
\end{aligned}
$$

where $\widehat{c}_{1}=-\left(\widehat{b}_{4}+\widehat{b}_{2}\right) /\left(\widehat{b}_{1}-1\right), \widehat{c}_{1, f}=-\left(\widehat{b}_{4, f}+\widehat{b}_{2, f}\right) /\left(\widehat{b}_{1}-1\right), \widehat{c}_{2}=-\left(\widehat{b}_{5}+\widehat{b}_{3}\right) /\left(\widehat{b}_{1}-1\right)$, $\widehat{c}_{2, f}=-\left(\widehat{b}_{5, f}+\widehat{b}_{3, f}\right) /\left(\widehat{b}_{1}-1\right), \widehat{c}_{3}=-\left(\widehat{b}_{8}+\widehat{b}_{6}\right) /\left(\widehat{b}_{1}-1\right), \widehat{c}_{3, f}=-\left(\widehat{b}_{8, f}+\widehat{b}_{6, f}\right) /\left(\widehat{b}_{1}-1\right)$, $\widehat{c}_{4}=-\left(\widehat{b}_{9}+\widehat{b}_{7}\right) /\left(\widehat{b}_{1}-1\right)$ and $\widehat{c}_{4, f}=-\left(\widehat{b}_{9, f}+\widehat{b}_{7, f}\right) /\left(\widehat{b}_{1}-1\right)$. Provided that a stable relationship between the exchange rate and the fundamentals exists, the set of coefficients $c$ in this equation is equivalent to the set of coefficients $a$ in the modified flexible-price model. Thus, in fact we test the short-run dynamic equation

$$
\begin{aligned}
\Delta e_{t}= & \widehat{b}_{0}+\widehat{b}_{2} \Delta m_{t}+\widehat{b}_{2, f} \Delta m_{t}^{*}+\widehat{b}_{3} \Delta y_{t}+\widehat{b}_{3, f} \Delta y_{t}^{*} \\
& +\widehat{b}_{6} \Delta \widehat{h}_{m, t}+\widehat{b}_{6, f} \Delta \widehat{h}_{m^{*}, t}+\widehat{b}_{7} \Delta \widehat{h}_{y, t}+\widehat{b}_{7, f} \Delta \widehat{h}_{y^{*}, t} \\
& +\left(\widehat{b}_{1}-1\right) \varepsilon_{t-1}+\nu_{t} .
\end{aligned}
$$

It should also be noted that as first differencing is sufficient to produce stationary series and as there exists a cointegration relationship shown in Table 2 and 3 , the residual term $\nu_{t}$ is an $I(0)$ series.

As stated in Greene (2000), the movement of the exchange rate from the previous period associates with the changes in the fundamentals along the long-run equilibrium corrected for the previous deviation from the long-run equilibrium. This equation contains an equilibrium relationship in the first two lines and an adjustment for the deviation from the previous equilibrium in the last line. Table 5 shows that there exists a correction mechanism of equilibrium errors towards the long-run equilibrium, as $\left(\widehat{b}_{1}-1\right)$ is significantly negative, except in the case of Italy. The error correction term, $\varepsilon_{t-1}$, is significantly negative at the $5 \%$ significance level in the case of Canada and at the $1 \%$ significance level for France, Japan and the UK. In the case of Italy, counter-intuitively, at the monthly horizon there is no significant adjustment towards long-run equilibrium. Furthermore, in the short run the exchange rate can be significantly explained by changes in the US real income. Yet, other macroeconomic fundamentals as well as their uncertainty fail to explain the exchange rate in the short run.

${ }^{27}$ For example, see Levy and Sarnat (1970) and Solnik (1974). 
Table 5: Parameters of the modified sticky-price model

$$
\begin{aligned}
\Delta e_{t}= & \widehat{b}_{0}+\left(\widehat{b}_{1}-1\right) \varepsilon_{t-1}+\widehat{b}_{2} \Delta m_{t}+\widehat{b}_{2, f} \Delta m_{t}^{*}+\widehat{b}_{3} \Delta y_{t}+\widehat{b}_{3, f} \Delta y_{t}^{*} \\
& +\widehat{b}_{6} \Delta \widehat{h}_{m, t}+\widehat{b}_{6, f} \Delta \widehat{h}_{m^{*}, t}+\widehat{b}_{7} \Delta \widehat{h}_{y, t}+\widehat{b}_{7, f} \Delta \widehat{h}_{y^{*}, t}+\nu_{t}
\end{aligned}
$$

\begin{tabular}{cccccc}
\hline & Canada & France & Italy & Japan & UK \\
\cline { 2 - 6 }$\widehat{b}_{0}$ & 0.001 & $2.37 \mathrm{E}-4$ & 0.003 & -0.002 & 0.001 \\
$\left(\widehat{b}_{1}-1\right)$ & $-0.023^{* *}$ & $-0.056^{* * *}$ & -0.027 & $-0.063^{* * *}$ & $-0.087^{* * *}$ \\
$\widehat{b}_{2}$ & 0.042 & -0.024 & -0.083 & 0.021 & -0.067 \\
$\widehat{b}_{2, f}$ & -0.055 & -0.071 & 0.040 & $-0.189^{*}$ & 0.003 \\
$\widehat{b}_{3}$ & 0.070 & -0.109 & 0.009 & -0.050 & -0.078 \\
$\widehat{b}_{3, f}$ & $0.207^{* *}$ & $0.502^{* *}$ & $0.481^{* *}$ & 0.084 & $0.675^{* * *}$ \\
$\widehat{b}_{6}$ & 9.119 & -10.505 & -56.871 & 75.438 & $-159.643^{*}$ \\
$\widehat{b}_{6, f}$ & 138.630 & 33.414 & 59.534 & -210.013 & -229.840 \\
$\widehat{b}_{7}$ & 17.408 & 22.570 & -3.041 & 12.068 & -10.498 \\
$\widehat{b}_{7, f}$ & -28.122 & -75.073 & -4.561 & -21.820 & -42.507
\end{tabular}

This table gives the estimation results of the modified sticky-price model, based the linear OLS regression. An asterisk, two asterisks and three asterisks indicate significance at the $10 \%, 5 \%$ and $1 \%$ level of significance, respectively.

\section{Conclusion}

The expectations regarding macroeconomic circumstances may influence the exchange rate in the manner predicted by the monetary models. Yet, the random walk assumption might be too naive for the market expectations. In this paper, we propose an alternative expectation formation process for the macroeconomic variables by introducing additional risk factors, based on the volatility of the macroeconomic fundamentals. As the fundamentals empirically exhibit a mean-reverting process with persistent memory in the standard deviation (representing the adjustment and speed towards the mean), a nonlinearity in the expectation formation process is present. To capture the exchange rate volatility, in addition to the traditional fundamentals, like money supply and real income, time variation in the second moments of these fundamentals are incorporated to describe the expected exchange rate returns.

We find significant cointegration between the variables in the modified flexibleprice monetary model, while there is evidence for the correction of equilibrium errors towards the long-run equilibrium in the modified sticky-price model. In the long run, an increase in the domestic money supply or a decrease in the foreign money supply tends to depreciate the domestic currency. Higher domestic output or lower foreign output is likely to appreciate the domestic currency. The impacts of macroeconomic sources of risk are also significant. Uncertainty about the economy lowers the demand for the currency and subsequently depreciates the currency, relative to the fundamental-based value. From an asset pricing perspective, increased risk is accompanied by increased expected future returns, leading to a current depreciation of the currency. Our findings indicate that macroeconomic sources of FOREX risk seem to be a missing factor in exchange rate studies, and strongly suggest that the monetary exchange rate models are still potentially useful. 


\section{Appendix A: Data Sources}

The data applied in this paper are monthly observations of exchange rates, money supply and industrial production, starting from June 1973 (after the breakdown of the Bretton Woods system) to December 1998. There are six OECD countries studied, which are Canada, France, Italy, Japan, the United Kingdom (UK) and the United States (US). Both European and non-European countries, with pos sible different economic mechanisms, are selected based on the availability of the required data. The US dollar is used as a vehicle currency and the US variables are used in the paper as the foreign variables.

The main data source is the IMF International Financial Statistics (IFS), except for M1 of the US. This time series is from the United States Federal Reserve Bank at St. Louis. It is compared with available quarterly series from the IFS and they are very similar. The US dollar exchange rates (domestic currency prices per one US dollar) from the IFS are coded 'AE'. Monetary aggregation is represented by seasonally unadjusted M1 data from IFS coded 34, except for the UK. According to purpose of the paper, liquidity under the central bank's controllability is preferable. For the UK, we decide to use $\mathrm{M}_{0}$, coded 59 , instead of another available choice $\mathrm{M}_{4}$. Seasonally adjusted industrial production, coded 66 , is used as a proxy for real income. If necessary, an additive seasonal moving average approach is used for the seasonal adjustment.

\section{Appendix B: The Reduced-form Solutions of the Exchange Rate Models}

The flexible-price model is derived from the simple quantity equation $M_{t} V_{t}=$ $P_{t} Y_{t}$. In logarithms, the quantity equation reveals

$$
m_{t}+v_{t}=p_{t}+y_{t}
$$

where $m_{t}, v_{t}, p_{t}$ and $y_{t}$ are the logarithms of the money supply, the money velocity, the price level and the real income at period $t$ respectively. We assume further that purchasing power parity (PPP) and uncovered interest parity (UIP) hold.

The stochastic PPP assumption, which is a more specific version of the noarbitrage assumption, is defined as

$$
p_{t}=\tau+p_{t}^{*}+e_{t}+\omega_{t}
$$

In equation (12), $e_{t}, p_{t}$ and $p_{t}^{*}$ are the logarithms of the nominal exchange rate, i.e., the price of a unit of foreign currency, the domestic price level and the foreign price level respectively. An asterisk denotes a foreign variable, i.e., in this case a US variable. While $\tau$ is a constant and $\omega_{t}$ represents a stationary, zero mean disturbance term, sometimes referred to as the real exchange rate.

According to the UIP condition, the interest rate differential between domestic and foreign assets is supposed to be equal to the expected rate of depreciation of the domestic currency. The expected change in currency price that satisfies equilibrium in the capital markets can, thus, be written as

$$
E_{t}\left[e_{t+1}\right]-e_{t}=i_{t}-i_{t}^{*}
$$

where $i_{t}$ and $i_{t}^{*}$ are the domestic interest rate and the foreign interest rate respectively. $E_{t}[\cdot]$ is the conditional expectation operator.

The velocity of money circulation is presumed to be a stable function of real income and the interest rate. The logarithm of money velocity is linearly specified 
as a decreasing function of the logarithm of real income and an increasing function of the interest rate, i.e.,

$$
v_{t}=\theta-\gamma y_{t}+\varphi i_{t}+\varpi_{t}
$$

where $\theta$ is a constant and $\varpi_{t}$ is a stationary, zero mean disturbance.

Suppose that (11) holds at home and in foreign countries with an identical income elasticity, $\gamma$, and interest semi-elasticity, $\varphi$. Combine (11) with (12), (13) and (14) and rework for the foreign country, one finds

$$
e_{t}=-\tau+\frac{1}{1+\varphi} \widetilde{m}_{t}-\frac{(1+\gamma)}{1+\varphi} \widetilde{y}_{t}+\frac{\varphi}{1+\varphi} E_{t}\left[e_{t+1}\right]+\varepsilon_{t},
$$

where $\widetilde{x}_{t}=x_{t}-x_{t}^{*}$ and $\varepsilon_{t}=\varpi_{t}-\varpi_{t}^{*}-\omega_{t}$.

To solve this linear equation with rational expectation, we apply the law of iterated expectations, see Samuelson (1965) and Blanchard and Fischer (1993). For simplicity, we rewrite equation (15) as

$$
e_{t}=\varsigma_{0}+\varsigma_{1} \widetilde{f}_{t}+\varsigma_{2} E_{t}\left[e_{t+1}\right]+\varepsilon_{t}
$$

where $\varsigma_{0}=-\tau, \varsigma_{1}=\frac{1}{1+\varphi}, \varsigma_{2}=\frac{\varphi}{1+\varphi}$, and $\widetilde{f}_{t}=\widetilde{m}_{t}-(1+\gamma) \widetilde{y}_{t}$. Note that $\varsigma_{2}=1-\varsigma_{1}$ and that $\varsigma_{1}$ and $\varsigma_{2} \in(0,1)$ as $0<\varphi<1$, see Flood, Rose and Mathieson (1991) and Flood and Rose (1995). Equation (16) implies that the exchange rate depends on its expected rate for the next period, $E_{t}\left[e_{t+1}\right]$, and on the current fundamentals, $\widetilde{f}_{t}$, with the weights summing up one. According to the law of iterated expectations, we have

$$
e_{t}=\varsigma_{0} \sum_{i=0}^{T} \varsigma_{2}^{i}+\varsigma_{1} \sum_{i=0}^{T} \varsigma_{2}^{i} E_{t}\left[\widetilde{f}_{t+i}\right]+\varsigma_{2}^{T+1} E_{t}\left[e_{t+T+1}\right]+\sum_{i=0}^{T} \varsigma_{2}^{i} E_{t}\left[\varepsilon_{t+i}\right]
$$

We then assume further that as the horizon $T$ increases, the exchange rate at $T+1$ periods from now becomes negligeable, or equivalently the rational bubble shrinks to zero and that $E_{t}\left[\varepsilon_{t+i}\right]=0$.

As $T$ tends to infinity,

$$
\lim _{T \rightarrow \infty} \varsigma_{2}^{T+1} E_{t}\left[e_{t+T+1}\right]=0
$$

and the solution becomes:

$$
e_{t}=\varsigma_{0} \sum_{i=0}^{\infty} \varsigma_{2}^{i}+\varsigma_{1} \sum_{i=0}^{\infty} \varsigma_{2}^{i} E_{t}\left[\widetilde{f}_{t+i}\right]
$$

This equation is comparable to equation (2), and implies that the elasticity of the exchange rate with respect to its expected fundamentals declines as looking further into the future, as

$$
\lim _{t \rightarrow \infty} \varsigma_{2}^{t}=0
$$

Moreover, for equation (18) to converge it requires that the logarithm of fundamentals, $\widetilde{f}$, grows at rate lower than $\varsigma_{1} /\left(1-\varsigma_{1}\right)$, i.e., $1 / \varphi$, otherwise the solution (19) would be explosive.

The sluggish-price model is an extension of the flexible-price model with inertia introduced into the price mechanism, instead of relying on perfectly flexible prices. Empirically, there are deviations from purchasing power parity in equation (12), in which $\omega_{t}$ are large and persistent. There is also strong correlation between nominal and real exchange rates. In Dornbusch's (1976) sluggish-price model, the 
expected exchange rate return is formed as the discrepancy between the long run rate $\bar{e}$, to which the economy will eventually converge, and the current spot rate $e$. Mathematically,

$$
E[e]-e=\delta(\bar{e}-e), 0<\delta<1 .
$$

To allow for sticky prices, the Phillips curve equation is substituted in the place of purchasing power parity in equation (12), see, e.g., Obstfeld and Rogoff (1984), Frankel and Rose (1994) and Flood and Rose (1995). It is conventional to assume that in addition to the PPP condition, prices respond to the lagged excess demand in the good markets, $y_{t}-\bar{y}_{t}$, and shocks to the good markets, $g_{t}$ :

$$
p_{t+1}-p_{t}=\mu\left(y_{t}-\bar{y}_{t}\right)+g_{t}+E_{t}\left[\widehat{p}_{t+1}-\widehat{p}_{t}\right], 0<\mu<1,
$$

where $\bar{y}$ is the long-run output level, $g_{t}$ has zero mean and constant variance, and $\widehat{p}_{t}$ is the price level at time $t$ if prices were flexible and the good markets cleared.

$$
y_{t}-\bar{y}_{t}=\Theta\left(e_{t}+p_{t}^{*}-p_{t}\right)+\Phi r_{t}
$$

The excess demand is defined as an increasing function of real exchange rate, $\Theta>0$, and a decreasing function of the ex ante expected real interest rate, i.e., $r_{t} \equiv$ $i_{t}-E_{t}\left[p_{t+1}-p_{t}\right], \Phi<0$. Thus, by substituting equation (22) into equation (21) one gets

$$
p_{t+1}-p_{t}=\mu\left[\Theta\left(e_{t}+p_{t}^{*}-p_{t}\right)+\Phi r_{t}\right]+g_{t}+E_{t}\left[\widehat{p}_{t+1}-\widehat{p}_{t}\right] \text {. }
$$

Equation (23) displays the long-run equilibrium (when the purchasing power parity holds and thus, the left-hand-side (LHS) is equal to the last term on the righthand-side (RHS)) and its short-run dynamics (represented by deviations from the purchasing power parity by the first and the second terms on the RHS).

As in the long run $\widehat{p}=p, \widehat{p}$ can be defined by

$$
\mu\left[\Theta\left(e_{t}+p_{t}^{*}-\widehat{p}_{t}\right)+\Phi r_{t}\right]+g_{t}=0
$$

and thus,

$$
\begin{aligned}
p_{t+1}-p_{t}= & \mu\left[\Theta\left(e_{t}+p_{t}^{*}-p_{t}\right)+\Phi r_{t}\right]+g_{t}+E_{t}\left[p_{t+1}^{*}-p_{t}^{*}\right] \\
& +E_{t}\left[e_{t+1}-e_{t}\right]+\frac{\Phi}{\Theta} E_{t}\left[r_{t+1}-r_{t}\right]+\frac{1}{\mu \Theta} E_{t}\left[g_{t+1}-g_{t}\right] .
\end{aligned}
$$

Therefore, instead of using the purchasing power parity condition in equation (12) we substitute this price equation,

$$
\begin{aligned}
\widetilde{p}_{t}= & p_{t}-p_{t}^{*}=e_{t}+\frac{1}{\Theta \mu} E_{t}\left[e_{t+1}-e_{t}\right]+\frac{1}{\Theta \mu} E_{t}\left[p_{t+1}^{*}-p_{t}^{*}\right]-\frac{1}{\Theta \mu}\left(p_{t+1}-p_{t}\right) \\
+ & \frac{1}{\mu} \frac{\Phi}{\Theta^{2}} E_{t}\left[r_{t+1}-r_{t}\right]+\frac{\Phi}{\Theta} r_{t}+\frac{1}{\mu^{2} \Theta^{2}} E_{t}\left[g_{t+1}-g_{t}\right]+\frac{1}{\Theta \mu} g_{t},
\end{aligned}
$$

into the money demand equation, derived from the quantity equation (11) and the assumption of money circulation (14):

$$
\widetilde{p}_{t}=\widetilde{m}_{t}-(1+\gamma) \widetilde{y}_{t}+\widetilde{\varphi}_{t}+\widetilde{\varpi}_{t}
$$

Hence,

$$
\begin{aligned}
e_{t}= & \tilde{m}_{t}-(1+\gamma) \widetilde{y}_{t}+\varphi \widetilde{i}_{t}+\widetilde{\varpi}_{t} \\
& -\frac{1}{\Theta \mu} E_{t}\left[e_{t+1}-e_{t}\right]-\frac{1}{\Theta \mu} E_{t}\left[p_{t+1}^{*}-p_{t}^{*}\right]+\frac{1}{\Theta \mu}\left(p_{t+1}-p_{t}\right) \\
& -\frac{1}{\mu} \frac{\Phi}{\Theta^{2}} E_{t}\left[r_{t+1}-r_{t}\right]-\frac{\Phi}{\Theta} r_{t}-\frac{1}{\mu^{2} \Theta^{2}} E_{t}\left[g_{t+1}-g_{t}\right]-\frac{1}{\Theta \mu} g_{t} .
\end{aligned}
$$


To present the model in a common form as in equation (2), we assume the UIP condition (13) and the price process in equation (24). As a consequence, the exchange rate equation becomes

$$
\begin{aligned}
e_{t}= & \widetilde{k}_{t}+E_{t}\left[e_{t+1}\right] \\
& +\frac{(1-\theta) \varphi-\theta}{\theta \varphi} E_{t-1}\left[e_{t}\right]-\frac{(1-\theta) \varphi-\theta+1}{\theta \varphi} e_{t-1}+\psi_{t} .
\end{aligned}
$$

where $\widetilde{k}_{t}=\frac{1}{\varphi} \widetilde{f}_{t}+\frac{1-\theta}{\theta \varphi} \widetilde{f}_{t-1}, \psi_{t}=\frac{1}{\varphi} p_{t}^{*}-\frac{1}{\varphi} E_{t-1}\left[p_{t}^{*}\right]-\frac{\Omega}{\varphi} E_{t-1}\left[r_{t}\right]-\frac{(1-\theta \Omega)}{\theta \varphi} r_{t-1}-\frac{1}{\varphi} g_{t-1}-$ $\frac{\theta}{\varphi} E_{t-1}\left[g_{t}-g_{t-1}\right]$ and the fundamental $\widetilde{f}_{t}$ is defined as $\widetilde{f}_{t}=\widetilde{m}_{t}-(1+\gamma) \widetilde{y}_{t}$. The coefficients are assigned by $\theta=\frac{1}{\Theta \mu}$ and $\Omega=\frac{\Phi}{\Theta}$. To apply the law of iterated expectations to this second order difference equation, we define $A_{t}=e_{t}+\frac{(1-\theta) \varphi-\theta+1}{\theta \varphi} e_{t-1}$. Equation (26) can, then, be rewritten as

$$
A_{t}=\widetilde{k}_{t}+E_{t-1}\left[A_{t+1}\right]-\frac{1}{\theta \varphi} E_{t-1}\left[e_{t}\right]+\kappa_{t}+\psi_{t}
$$

in which $\kappa_{t}=E_{t}\left[e_{t+1}\right]-E_{t-1}\left[e_{t+1}\right]$.

By the law of iterated expectations one may get

$$
\begin{aligned}
A_{t}= & \widetilde{k}_{t}+\sum_{i=1}^{T} E_{t-1}\left[\widetilde{k}_{t+i}\right]-\frac{1}{\theta \varphi} \sum_{i=0}^{T} E_{t-1}\left[e_{t+i}\right]+E_{t-1}\left[A_{t+T+1}\right] \\
& +\sum_{i=0}^{T} E_{t-1}\left[\kappa_{t+i}\right]+\sum_{i=0}^{T} E_{t-1}\left[\psi_{t+i}\right]
\end{aligned}
$$

For simplicity, we presume that the expected exchange rate in any one period, i.e., $E_{t-1}\left[A_{t+T+1}\right]$, is only a small component in determining the current spot rate, and it becomes negligeable as the horizon $T$ rises. Furthermore, when $i \geq 0, E_{t-1}\left[\kappa_{t+i}\right]=$ $E_{t-1}\left[\psi_{t+i}\right]=0$. As a consequence, as $T$ tends to infinity the solution becomes

$$
e_{t}=\frac{(1+\varphi)(\theta-1)}{\theta \varphi} e_{t-1}+\widetilde{k}_{t}+\sum_{i=1}^{\infty} E_{t-1}\left[\widetilde{k}_{t+i}\right]-\frac{1}{\theta \varphi} \sum_{i=0}^{\infty} E_{t-1}\left[e_{t+i}\right]
$$

Equation (28) is like equation (19) in the flexible-price model, except there is inertia in the exchange rate equation. The exchange rate now depends on $\widetilde{k}_{t}$, namely current and lagged values of money supply and income, and its expected future fundamentals. Additionally, equation (28) is also rather similar to the sticky-price concept stated earlier and also a solution (4) from Cuthbertson (1999).

Appendix C: Adding Stochastic Volatility to the Fundamental Expectations

There may be many ways to incorporate the second moments of the fundamentals into their expectations. In this appendix, we show a few possible ways. In developing an explicit solution for the exchange rate, Hodrick (1989) assumes a conditionally lognormal data generating process for the fundamentals, and applies the fact that if $x$ has a lognormal distribution with $\log (x) \sim N\left(\mu, \sigma^{2}\right)$, its expectation reads $E[x]=e^{\mu+\frac{1}{2} \sigma^{2}}$. Hence, by loglinearization of his general equilibrium model one gets $\log (E[x])=\mu+\frac{1}{2} \sigma^{2}$, which is exploited in Hodrick (1989).

One could equivalently adopt the modified form of uncovered interest parity (UIP) that adjusts for a risk premium and specify a risk premium as a function of time-varying fundamental variances. This is alike the portfolio balance model, in which the UIP condition incorporates the risk premium as a function of relative asset holding in domestic and foreign bonds. By combining equation (15) with a 
modified version of UIP that has a time-varying risk premium $\rho_{t}$, and applying the law of iterated expectations, the exchange rate can be expressed as

$$
e_{t}=E_{t}\left[\widetilde{m}_{t+i}\right]-\beta E_{t}\left[\widetilde{y}_{t+i}\right]+\alpha E_{t}\left[\rho_{t+i}\right] .
$$

From the equation above, the exchange rates are determined by two components, which are the expectation regarding the future fundamental values and the expectation regarding risk from holding the currency. Intuitively, a deviation from its expected fundamental value needs an extra compensation. Accordingly, through a risk premium one can characterize risk in the FOREX markets by macroeconomic uncertainty.

Another technical approach is to apply Taylor's theorem. To make our point, we consider money supply process based on Lucas (1982) and Obstfeld (1987). Suppose $m_{t}=w_{t}+m_{t-1}$, where $m_{t}$ is the logarithmic level of money supply and $w_{t}$ is the stochastic growth rate of money supply. Obstfeld (1987) assumes that $w_{t}$ exhibits a jump process, i.e., $w_{t}=d_{t} \mu_{t}$, where $d_{t}$ represents a dummy variable indicating an occurrence of Poisson event, and $\mu_{t}$ denotes the volume of change. To describe money growth $w_{t}$, there are a number of possible Poisson processes, ranging from the simplest one with a constant probability to the one with unstable probability behavior where $d_{t}$ is a Markov Chain with an unabsorbing state.

Yet, in practice we know that the logarithmic first difference of the fundamentals, $m_{t}-m_{t-1}=\Delta m_{t}=d_{t} \mu_{t}$, is likely to be mean reverting. Hence, to proxy the movement of the variable $\Delta m_{t}$ around its mean one may apply Taylor's theorem to an arbitrary function, see Chiang (1984). If the mean is close to zero, one might use Maclaurin's series by expanding the function around the point $\Delta x=0$. To include the variance term in the fundamental expectation, one may expand the series to the second degree, which is rather conventional for Taylor's expansion. As a result, one can proxy the expected movement of the macroeconomic series by a nonlinear function.

\section{Appendix D: The Closed-form Solutions}

To introduce time-varying conditional variances of the macroeconomic variables into the exchange rate model, we assume that there is a relationship between the first and the second moments of the fundamentals. The fundamentals are assumed to have somewhat similar to ARCH-in-Mean (ARCH-M) processes. The ARCHM model, initiated by Engle, Lilien and Robins (1987), is originally used to describe the risk and return relationship of assets, as suggested in finance theory. For macroeconomic variables, there is rather weak evidence of ARCH-M process. ${ }^{28}$ An approximate linear relationship between the fundamental expectation and its variance is, however, intuitive.

Similar to the ARCH-M model, suppose the whole sequence of future fundamentals can be represented by its current value and its variance. If $x_{t}$ is the time series of interest, the model may read

$$
x_{t+1}=\gamma_{0}+\gamma_{1} x_{t}+\gamma_{2} h_{t+1}+u_{t+1},
$$

where $x$ represents a macroeconomic variable, $h$ is the conditional variance of the variable $x$, presumably time varying, and $u$ is a residual term. As the fundamentals empirically exhibit mean-reverting processes with persistent memory in standard deviations, time variation in the conditional variance may represent the adjustment and speed towards the mean.

In equation (29), the first component is like a random walk or an AR(1) process, which is often assumed for macroeconomic variables. The second component

\footnotetext{
${ }^{28}$ For example, in our data set only Canada and the UK show weak evidence of this feature.
} 
shows that macroeconomic uncertainty plays a role in the fundamental expectation formations. For example, the fundamental variances may represent economic circumstances, i.e., whether the economy is in volatile or tranquil periods, in which the expectations may be different. In turmoil (disequilibria), the monetary variables, e.g., money supply and interest rates, may be altered more often, and the state variables, e.g., income, unemployment rate and inflation rate, may be more volatile than in regular periods.

To capture time-varying conditional variances, for simplicity we use a GARCH $(1,1)$ model, i.e.,

$$
h_{t+1}=\lambda_{0}+\lambda_{1} u_{t}^{2}+\lambda_{2} h_{t}
$$

A GARCH $(1,1)$ model is often used to capture time-varying conditional variances of economic variables, see Bollerslev (1987). By using the law of iterated expectations, the expected future fundamentals can be described as

$$
\begin{aligned}
E_{t}\left[x_{t+i}\right] & =\gamma_{0} \sum_{s=0}^{i-1} \gamma_{1}^{s}+\gamma_{1}^{i} x_{t}+\gamma_{2} \sum_{s=0}^{i-1} \gamma_{1}^{s} E_{t}\left[h_{t+i-s}\right] \\
\text { while } E_{t}\left[h_{t+i-s}\right] & =\lambda_{0} \sum_{k=0}^{i-s-1}\left(\lambda_{1}+\lambda_{2}\right)^{k}+\left(\lambda_{1}+\lambda_{2}\right)^{i-s} h_{t} .
\end{aligned}
$$

Reorganizing gives a process of $x$ as a function of its current value and its conditional variance as follows:

$$
E_{t}\left[x_{t+i}\right]=\alpha_{0}+\alpha_{1} x_{t}+\alpha_{2} h_{t}
$$

where

$$
\begin{aligned}
\alpha_{0} & =\sum_{s=0}^{i-1} \gamma_{1}^{s}\left[\gamma_{0}+\gamma_{2} \lambda_{0} \sum_{k=0}^{i-s-1}\left(\lambda_{1}+\lambda_{2}\right)^{k}\right] \\
\alpha_{1} & =\gamma_{1}^{i} \\
\text { and } \alpha_{2} & =\gamma_{2} \sum_{s=0}^{i-1} \gamma_{1}^{s}\left[\left(\lambda_{1}+\lambda_{2}\right)^{i-s}\right] .
\end{aligned}
$$

Substitute the expectations for money supply and real income into equation (19) and rework with inertia in equation (28), one obtains equations (5) and (6), respectively. 


\section{References}

[1] Arnold, I.J.M., 1996, Empirical Essays in Monetary Economics, Ph.D. Thesis, Erasmus University Rotterdam.

[2] Backus, D., 1984, Empirical Models of the Exchange Rates: Separating the Wheat from the Chaff, Canadian Journal of Economics 17, 824-846.

[3] Baillie, R., and T. Bollerslev, 1987, The Story of Daily Exchange Rates: A Condition Variance Tale, Mimeo, Northwestern University.

[4] Baillie, R., and T. Bollerslev, 1989, Common Stochastic Trends in a System of Exchange Rates, Journal of Finance 44, 167-181.

[5] Bakshi, G.S., and Z. Chen, 1997, Equilibrium Valuation of Foreign Exchange Claims, Journal of Finance 52, 799-826.

[6] Basak, S., and M. Gallmeyer, 1998, Currency Prices, the Nominal Exchange Rates and Security Prices in a Two Country Dynamic Monetary Economy, Mathematical Finance 9, 1-30.

[7] Bekaert, G., 1996, The Time Variation in Risk and Return in Foreign Exchange Markets: A General Equilibrium Perspective, Review of Financial Studies 9, 427-470.

[8] Bilson, J., 1978, The Monetary Approach to the Exchange Rate: Some Empirical Evidence, Working paper, IMF.

[9] Blanchard, O.J., and S. Fischer, 1993, Lectures on Macroeconomics, Cambridge: the MIT Press.

[10] Bollerslev, T., 1987, A Conditional Heteroskedastic Time Series Model for Speculative Prices and Rate and Return, Review of Economics and Statistics $69,542-547$.

[11] Buiter, W., and M. Miller, 1982, Real Exchange Rate Overshooting and the Output Cost of Bringing Down Inflation, European Economic Review 18, 85123.

[12] Campbell, J.Y., A.W. Lo, and A.C. MacKinlay, 1997, The Econometrics of Financial Markets, Princeton: Princeton Press.

[13] Chiang, A.C., 1984, Fundamental Methods of Mathematical Economics, Singapore: McGraw-Hill.

[14] Chinn, M.D., and R.A. Meese, 1995, Banking on Currency Forecasts: How Predictable is Change in Money?, Journal of International Economics 38, 161178.

[15] Cragg, J., 1982, Estimation and Testing in Time Series Regression Models with Heteroscedastic Disturbances, Journal of Econometrics 20, 135-157.

[16] Cumperayot, P., 2002, International Financial Markets: Risk and Extremes, Ph.D. Thesis, Erasmus University Rotterdam.

[17] Cumperayot, P., N. Hyung, and C.G. de Vries 2002, Exchange Rate Volatility: Attributable to Economic Fundamentals?, Working paper, Erasmus University Rotterdam. 
[18] Cuthbertson, K., 1999, Quantitative Financial Economics (Stocks, Bonds and Foreign Exchange), New York: Wiley.

[19] Dornbusch, R., 1976, Expectations and Exchange Rate Dynamics, Journal of Political Economy 84, 1161-1176.

[20] Dougherty, C., 1992, Introduction to Econometrics, New York: Oxford University Press.

[21] Drost, F.C., and T.E. Nijman, 1993, Temporal Aggregation of GARCH Processes, Econometrica 61, 909-927.

[22] Engle, R.F., 1982, Autoregressive Conditional Heteroscedasticity with Estimates of the Variance of United Kingdom Inflations, Econometrica 50, 9871007.

[23] Engle, R.F., 1983, Estimates of the Variance of U.S. Inflations Based on the ARCH model, Journal of Money, Credit and Banking 15, 286-301.

[24] Engle, R.F., and T. Bollerslev, 1986, Modeling the Persistence of Conditional Variances, Econometric Reviews 5, 1-50.

[25] Engle, R.F., and C. Granger, 1987, Co-integration and Error Correction: Representation, Estimation and Testing, Econometrica 35, 251-276.

[26] Engle, R.F., D. Lilien, and R. Robins, 1987, Estimating Time Varying Risk Premia in the Term Structure: The ARCH-M Model, Econometrica 55, 391407.

[27] Flood, R.P., and A.K. Rose, 1995, Fixing Exchange Rates; A Virtual Quest for Fundamentals, Journal of Monetary Economics 36, 3-37.

[28] Flood, R.P., and A.K. Rose, 1999, Understanding Exchange Rate Volatility without the Contrivance of Macroeconomics, Economic Journal 109, 660-672.

[29] Flood, R.P., A.K. Rose, and D.J. Mathieson, 1991, An Empirical Exploration of Exchange-Rate Target Zones, Carnegie-Rochester Series on Public policy $35,7-66$.

[30] Frankel, J.A., 1979, On the Mark: A Theory of Floating Exchange Rates Based on Real Interest Differentials, American Economic Review 69, 601-622.

[31] Frankel, J.A., and A. Meese, 1987, Are Exchange Rates Excessively Variable?, NBER Macroeconomics Annual 2, 117-153.

[32] Frenkel, J.A., 1976, A Monetary Approach to the Exchange Rate: Doctrinal Aspects and Empirical Evidence, Scandinavian Journal of Economics 78, 200224.

[33] Froot, K., and M. Obstfeld, 1991, Intrinsic Bubbles: The Case of Stock Prices, American Economic Review 81, 1189-1217.

[34] Greene. W.H., 2000, Econometric Analysis (fourth edition), New York: Prentice Hall.

[35] Groen, J.J.J., 1999, Long Horizon Predictability of Exchange Rates: Is it for Real?, Empirical Economics 24, 451-469.

[36] Hamilton, J., 1994, Time Series Analysis, Princeton: Princeton University Press. 
[37] Hodrick, R.J., 1978, An Empirical Analysis of the Monetary Approach to the Determination of the Exchange Rate, Reading: Addison-Wesley, 97-116.

[38] Hodrick, R.J., 1989, Risk, Uncertainty, and Exchange Rates, Journal of Monetary Economics 23, 433-459.

[39] Johansen, S., 1988, Statistical Analysis of Cointegration Vectors, Journal of Economic Dynamics and Control 12, 231-254.

[40] Krugman, P.R., and M. Obstfeld, 1997, International Economics: Theory and Policy (fourth edition), New York: Addison Wesley.

[41] Levy, H., and M. Sarnat, 1970, International Diversification of Investment Portfolios, American Economic Review 60, 668-675.

[42] Lintner, J., 1965, The Valuation of Risk Assets and the Selection of Risky Investments in Stock Portfolios and Capital Budgets, Review of Economics and Statistics 47, 425-442.

[43] Lucas, R.E. Jr., 1982, Interest rates and Currency Prices in a Two-country World, Journal of Monetary Economics 10, 335-360.

[44] MacDonald, R., and M. Taylor, 1994, The Monetary Model of the Exchange Rate: Long-run Relationship, Short-run Dynamics and How to Beat a Random Walk, Journal of International Money and Finance 13, 276-290.

[45] Mark, N.C., 1995, Exchange Rates and Fundamentals: Evidence on LongHorizon Predictability, American Economic Review 85, 201-218.

[46] Markowitz, H., 1959, Portfolio Selection: Efficient Diversification of Investments, New York: John Wiley.

[47] Meese, R.A., 1990, Currency Fluctuations in the Post-Bretton Woods Era, Journal of Economic Perspectives 4, 117-131.

[48] Meese, R.A., and K. Rogoff, 1983, Empirical Exchange Rate Models of the Seventies: Do They Fit Out of Sample, Journal of International Economics 14, 3-24.

[49] Meese, R., and K. Rogoff, 1988, Was It Real? The Exchange Rate-Interest Differential Relationship Over the Modern Floating rate Period, Journal of Finance 43-4, 933-948.

[50] Mussa, M., 1976, The Exchange Rate, the Balance of Payments, and Monetary and Fiscal Policy Under a Regime of Controlled Floating, Scandinavian Journal of Economics 78, 229-248.

[51] Mussa, M., 1979, Empirical Regularities in the Behavior of Exchange Rates and Theories of the Foreign Exchange Market, Policies for Employment, Prices and Exchange Rates, New York: North-Holland, 9-57.

[52] Obstfeld, M., 1987, Peso Problems, Bubbles, and Risk in the Empirical Assessment of Exchange-Rate Behavior, Working Paper 2203, NBER.

[53] Obstfeld, M., and K. Rogoff, 1984, Exchange Rate Dynamics with Sluggish Prices under Alternative Price-Adjustment Rules, International Economic Review 25, 159-174. 
[54] Osterwald-Lenum, M., 1992, A Note with Quantiles of the Asymptotic Distribution of the Maximum Likelihood of Cointegration Rank Statistics, Oxford Bulletin of Economics and Statistics 54, 461-471.

[55] Pagan, A., 1984, Econometric Issues in the Analysis of Regressions with Generated Regressors, International Economic Review 25, 221-247.

[56] Phillips, P.C.B., and M. Loretan, 1991, Estimating Long-Run Equilibria, Review of Economic Studies 58, 407-436.

[57] Ross, S., 1976, The Arbitrage Theory of Capital Asset Pricing, Journal of Economic Theory 13, 341-360.

[58] Saikkonen, P., 1991, Asymptotically Efficient Estimation of Cointegrating Regressions, Econometric Theory 7, 1-21.

[59] Samuelson, P., 1965, Proof that Properly Anticipated Prices Fluctuate Randomly, Industrial Management Review 6, 41-19.

[60] Sharpe, W., 1964, Capital Asset Prices: A Theory of Market Equilibrium under Conditionals of Risk, Journal of Finance 19, 425-442.

[61] Solnik, B., 1974, The International Price of Risk: An Empirical Investigation of the World Capital Market Structure, Journal of Finance 29, 365-378.

[62] Stock, J.H., and M. Watson, 1988, Testing for Common Trends, Journal of the American Statistical Association 83, 1097-1107.

[63] Stock, J.H., and M. Watson, 1993, A Simple Estimator of Cointegration Vectors in Higher Order Integrated Systems, Econometrica 61, 783-820.

[64] Stockman, A., 1980, A Theory of Exchange Rate Determination, Journal of Political Economy 88, 673-698.

[65] Svensson, L.E.O., 1985 a, Currency Prices, Terms of Trade, and Interest Rates: A General Equilibrium Asset Pricing Cash-in-advance Approach, Journal of International Economics 18, 17-42.

[66] Svensson, L.E.O., 1985 b, Money and Asset Prices in a Cash-in-advance Economy, Journal of Political Economy 93, 919-944. 


\title{
CESifo Working Paper Series
}

\author{
(for full list see www.cesifo.de)
}

837 Carola Grün and Stephan Klasen, Growth, Income Distribution, and Well-Being: Comparisons across Space and Time, January 2003

838 Robert S. Chirinko and Ulf von Kalckreuth, On the German Monetary Transmission Mechanism: Interest Rate and Credit Channels for Investment Spending, January 2003

839 Sascha O. Becker, Andrea Ichino, and Giovanni Peri, How Large is the "Brain Drain" from Italy?", January 2003

840 Albert Berry and John Serieux, All About the Giants: Probing the Influences on Growth and Income Inequality at the End of the $20^{\text {th }}$ Century, January 2003

841 Robert Fenge and Martin Werding, Ageing and the Tax Implied in Public Pension Schemes: Simulations for Selected OECD Countries, January 2003

842 Robert Fenge and Martin Werding, Ageing and Fiscal Imbalances Across Generations: Concepts of Measurement, January 2003

843 Giovanni Andrea Cornia, The Impact of Liberalisation and Globalisation on Income Inequality in Developing and Transitional Economies, January 2003

844 Peter Fredriksson and Per Johansson, Program Evaluation and Random Program Starts, January 2003

845 Bernd Hayo and Matthias Wrede, Fiscal Equalisation: Principles and an Application to the European Union, January 2003

846 Syed M. Ahsan and Jaideep Oberoi, Inequality, Well-being and Institutions in Latin America and the Caribbean, January 2003

847 Chang Woon Nam and Doina Maria Radulescu, The Role of Tax Depreciation for Investment Decisions: A Comparison of European Transition Countries, January 2003

848 V. Bhaskar and Steinar Holden, Wage Differentiation via Subsidised General Training, January 2003

849 Paloma Lopez-Garcia, Labour Market Performance and Start-up Costs: OECD Evidence, January 2003

850 Christian Keuschnigg and Soren Bo Nielsen, Public Policy for Start-up Entrepreneurship with Venture Capital and Bank Finance, January 2003

851 Yin-Wong Cheung, Menzie D. Chinn, and Eiji Fujii, China, Hong Kong, and Taiwan: A Quantitative Assessment of Real and Financial Integration, January 2003 
852 Gregory D. Hess, The Economic Welfare Cost of Conflict: An Empirical Assessment, February 2003

853 Douglas J. Cumming and Jeffrey G. MacIntosh, Comparative Venture Capital Governance. Private versus Labour Sponsored Venture Capital Funds, February 2003

854 Eckhard Janeba and John Douglas Wilson, Decentralization and International Tax Competition, February 2003

855 Tapio Palokangas, Capital Accumulation and Employment Cycles in a Model of Creative Destruction, February 2003

856 Brendan Walsh, When Unemployment Disappears: Ireland in the 1990s, February 2003

857 Luis H. R. Alvarez and Erkki Koskela, A General Approach to the Stochastic Rotation Problem with Amenity Valuation, February 2003

858 Christian Schultz, Strategic Campaigns and Redistributive Politics, February 2003

859 Ernst Fehr and Joseph Henrich, Is Strong Reciprocity a Maladaptation? On the Evolutionary Foundations of Human Altruism, February 2003

860 Haizhou Huang, Dalia Marin, and Chenggang Xu, Financial Crisis, Economic Recovery and Banking Development in Former Soviet Union Economies, February 2003

861 Pedro Cardoso and Bernard M.S. van Praag, How Sustainable Are Old-age Pensions in a Shrinking Population with Endogenous Labour Supply?, February 2003

862 Volker Meier, Efficient Transfer of Aging Provisions in Private Health Insurance, February 2003

863 Edward Castronova, Theory of the Avatar, February 2003

864 Robert S. Chirinko, Hans van Ees, Harry Garretsen, and Elmer Sterken, Investor Protections and Concentrated Ownership: Assessing Corporate Control Mechanisms in the Netherlands, February 2003

865 Bernard M.S. van Praag and Pedro Cardoso, The Mix Between Pay-as-you-go and Funded Pensions and what Demography has to do with it, February 2003

866 Ernst Fehr, Urs Fischbacher, Bernhard von Rosenbladt, Jürgen Schupp, and Gert G. Wagner, A Nation-Wide Laboratory. Examining Trust and Trustworthiness by Integrating Behavioral Experiments into Representative Survey, February 2003

867 Frank Heinemann, The Inflationary Impact of Wage Indexation, February 2003

868 Eytan Sheshinski, Bounded Rationality and Socially Optimal Limits on Choice in a Self-Selection Model, February 2003 
869 M. Hashem Pesaran, Estimation and Inference in Large Heterogenous Panels with Cross Section Dependence, February 2003

870 Luis H. R. Alvarez and Erkki Koskela, On the Tree-Cutting Problem under Interest Rate and Forest Value Uncertainty, February 2003

871 Norbert Berthold and Rainer Fehn, Unemployment in Germany: Reasons and Remedies, February 2003

872 Clemens Fuest, Bernd Huber, and Philipp Tilleßen, Tax Policy and Entrepreneurship in the Presence of Asymmetric Information in Capital Markets, February 2003

873 Eytan Sheshinski, Optimum and Risk-Class Pricing of Annuities, February 2003

874 Willi Leibfritz, Paul O'Brien and Jean-Christophe Dumont, Effects of Immigration on Labour Markets and Government Budgets - An Overview, February 2003

875 M. Hashem Pesaran and Allan Timmermann, How Costly is it to Ignore Breaks when Forecasting the Direction of a Time Series?, February 2003

876 Thorvaldur Gylfason and Gylfi Zoega, Education, Social Equality and Economic Growth: A View of the Landscape, February 2003

877 Robin Boadway and Jean-François Tremblay, Public Economics and Startup Entrepreneurs, February 2003

878 Erkki Koskela and Roope Uusitalo, The Un-Intended Convergence: How the Finnish Unemployment Reached the European Level, February 2003

879 Robert Fenge and Volker Meier, Pensions and Fertility Incentives, February 2003

880 Eytan Sheshinski, Note on Income Taxation and Occupational Choice, February 2003

881 A B Atkinson, Income Inequality in OECD Countries: Data and Explanations, February 2003

882 Thomas Gehrig and Rune Stenbacka, Venture Cycles: Theory and Evidence, February 2003

883 Ralf Becker and Thomas Hellmann, The Genesis of Venture Capital - Lessons from the German Experience, March 2003

884 Eytan Sheshinski, Note on the Optimum Pricing of Annuities, March 2003

885 Paul De Grauwe and Magdalena Polan, Globalisation and Social Spending, March 2003

886 F. van der Ploeg, Do Social Policies Harm Employment and Growth?, March 2003

887 Mirjam van Praag, Initial Capital Constraints Hinder Entrepreneurial Venture Performance: An empirical analysis, March 2003 
888 Bernard Steunenberg, Coordinating Sectoral Policymaking: Searching for Countervailing Mechanisms in the EU Legislative Process, March 2003

889 Eytan Sheshinski, Optimum Delayed Retirement Credit, March 2003

890 Frederick van der Ploeg, Rolling Back the Public Sector - Differential effects on employment, investment and growth, March 2003

891 Paul De Grauwe and Marc-Alexandre Sénégas, Monetary Policy in EMU when the Transmission is Asymmetric and Uncertain, March 2003

892 Steffen Huck and Kai A. Konrad, Strategic Trade Policy and the Home Bias in Firm Ownership Structure, March 2003

893 Harry Flam, Turkey and the EU: Politics and Economics of Accession, March 2003

894 Mathias Hoffmann and Ronald MacDonald, A Re-examination of the Link between Real Exchange Rates and Real Interest Rate Differentials, March 2003

895 Badi H. Baltagi, Espen Bratberg, and Tor Helge Holmås, A Panel Data Study of Physicians' Labor Supply: The Case of Norway, March 2003

896 Dennis C. Mueller, Rights and Citizenship in the European Union, March 2003

897 Jeremy Edwards, Gains from Trade in Tax Revenue and the Efficiency Case for Trade Taxes, March 2003

898 Rainer Fehn and Thomas Fuchs, Capital Market Institutions and Venture Capital: Do They Affect Unemployment and Labour Demand?, March 2003

899 Ronald MacDonald and Cezary Wójcik, Catching Up: The Role of Demand, Supply and Regulated Price Effects on the Real Exchange Rates of Four Accession Countries, March 2003

900 R. Selten, M. Schreckenberg, T. Pitz, T. Chmura, and S. Kube, Experiments and Simulations on Day-to-Day Route Choice-Behaviour, April 2003

901 Stergios Skaperdas, Restraining the Genuine Homo Economicus: Why the Economy Cannot be Divorced from its Governance, April 2003

902 Yin-Wong Cheung, Menzie D. Chinn, and Antonio Garcia Pascual, What Do We Know about Recent Exchange Rate Models? In-Sample Fit and Out-of-Sample Performance Evaluated, April 2003

903 Mika Widgrén, Enlargements and the Principles of Designing EU - Decision-Making Procedures, April 2003

904 Phornchanok Cumperayot, Dusting off the Perception of Risk and Returns in FOREX Markets, April 2003 